\title{
Organic membranes and related molecular separation processes: input in Energy and Environment areas
}

\author{
$\underline{\text { D. Roizard }}^{1}$, E. Favre ${ }^{1}$, V. Teplyakov ${ }^{2}$ and V. Khotimsky ${ }^{2}$ \\ ${ }^{1}$ Laboratoire des Sciences du Génie Chimique, Nancy-Université, CNRS \\ 1, rue Grandville B.P. 20451 F-54001 Nancy FRANCE \\ ${ }^{2}$ Topchiev Institute of Petroleum Synthesis, RAS, 29, Leninsky pr. 119991 Moscox, RUSSIA \\ <Denis.Roizard@ensic.inpl-nancy.fr> <tepl@ips.ac.ru>
}

\section{Introduction}

Achieving separation tasks to characterize new molecules or to produce added value components is often very difficult, either at the lab scale or at the industrial level: it is time consuming, costs lot money and may require sophisticated engineering processes. Generally speaking, separation can involve several types of media, going from solids, liquid-solid or even to liquids or gas mixtures. Obviously the more the constituents are alike the worse is generally the selectivity and the highest the overall cost. Among illustrative samples one can think about racemic resolution and isotope enrichment that would really be the top of the separation art.

Achieving efficient and smart separations using membranes has long been restricted to biological systems, such as cellular membranes. Nevertheless, since 1970's, polymeric membranes and membranes processes came into the game and demonstrated first on the lab bench and then in the industry their interest, their potential and their efficiency for the separation of mixtures at the molecular level [1-2]. Going from the molecular structure of polymers to the main features of membranes processes, this paper highlights the efficiency of organic membranes to separate gas mixtures such as inert gas $\left(\mathrm{H}_{2}, \mathrm{~N}_{2}\right)$ and organic molecules (hydrocarbons, VOC's) showing the membrane input and the striking interest of membrane processes in the field of energy and environmental protection [3].

\section{Permeation principles}

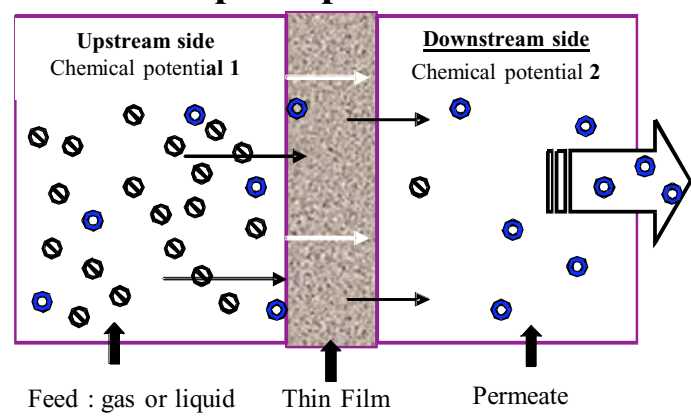

Fig. 1: Membrane separation scheme
To understand how an apparently simple thin film of polymer can induce molecular separation, one should be aware of the fundamental mechanism involved [4]. First to reach this level of separation it is obvious that only no porous films could be used, which means that no direct sieving effect is involved like in micro- or ultra- or nanofiltration. That is why the mechanism widely recognized is called the "solution-diffusion" mechanism [4]. It postulates a permeation based on three steps:
mide of the membrane, then diffusion in the bulk initial sorption of molecules at the upstream side of the membrane, then diffusion in the bulk
of the polymer network and at last de-sorption at the downstream side according to the activity gradient of the molecules (cf Fig.1).

Thus the permeability coefficient of a thin film can be quantified as $\mathscr{P}=$ Sorption $x$ Diffusion

\section{Materials and Method}

Two different membranes were tested, i.e. block[-(polydimethylsiloxane)-(2,4-ureatolylene)] copolymer (BPDMS) prepared at LSGC-Nancy and poly(1-trimethylsilyl-1-propyne) (PTMSP) developed at TIPS (Fig.2). BPDMS behaves essentially as a rubbery polymer, having permeation properties similar to polydimethylsiloxane (PDMS) [5] but with enhanced mechanical properties than PDMS. Conversely PTMSP is a glassy polymer synthesized with a particular method using a Nobium catalyst as to better control the polymer chain structure. 
It is known that PTMSP possesses the highest permeability properties among glassy and even rubbery polymers in relation with its particular self organized matrix which gives rise nano voids [6].

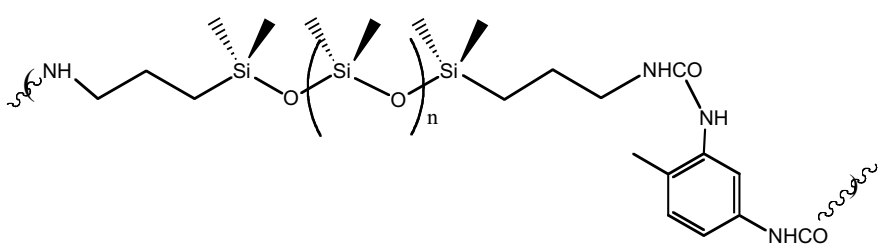

BPDMS

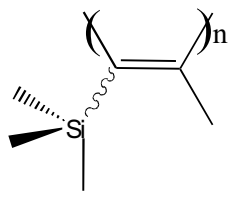

PTMSP cis/trans-ratio of $60 / 40\left({ }^{13} \mathrm{C}\right.$ NMR $)$

Figure 2: Chemical structures of BPDMS and PTMSP

Vapour permeabilities were measured versus the activity of vapour using a barometric method with polymer films of about $0.012 \mathrm{~m}^{2}$ and $80 \mu \mathrm{m}$ thickness (Fig.3). Gas permeation data for $\mathrm{H}_{2}$ and $\mathrm{N}_{2}$ were recorded according the time-lag method as described elsewhere [7].

\begin{tabular}{|l|l|} 
Figure 3: Vapour permeation setup \\
A given vapour pressure is generated at constant \\
temperature from the liquid reservoir and sent to the \\
upstream side of the cell compartment. Vapour \\
permeates partly to the downstream side and is \\
quenched in liquid $\mathrm{N} 2$ traps to under low pressure. \\
1. Cell with membrane 2. Liquid reservoir \\
3. Vacuum pump \\
Vapour generation / Cell / Trapping compartment \\
5. Vacuum gauge
\end{tabular}

\section{Results and discussion}

To evaluate the intrinsic potential of a polymer for membrane processes, the permeability coefficient of pure gas can be easily measured with the time lag method under standard conditions, generally 2-3 bars at the membrane upstream side and vacuum at the downstream side at $25^{\circ} \mathrm{C}$. The permeability $P$ can be defined as the permeate flux normalized to the partial gas pressure and to the membrane thickness (z), i.e. $\mathcal{P}=\mathrm{J} . \mathrm{z} / \Delta \mathrm{P}$; the practical unit is the Barrer, equivalent to $7.5 .10^{-5} \mathrm{~m}^{2}(\mathrm{STP}) \mathrm{m} \cdot \mathrm{m}^{-2} \mathrm{~s}^{-1} \mathrm{kPa}^{-1}$. Hence the ratio of the permeability coefficients data leads to the ideal selectivity (noted $\alpha^{*}$ ) of a given polymer for the considered binary gas mixture. As far as inert gas are concerned, the ideal selectivity is generally a good approximation of the membrane separation potential because in that case the dominant parameter of the permeability is the diffusion one. One the other hand, vapour and liquid permeation can induced strong sorption effects, leading thus to more complex permeation mechanisms resulting in deviations from pure flux. In such cases, the real selectivity is much lower than the ideal one.

The characterizations of BPDMS and PTMPS membrane properties are gathered in the Tab.1.

\begin{tabular}{|c|c|c|c|c|c|c|c|c|c|c|c|}
\hline & $\mathrm{N}_{2}$ & $\mathrm{O}_{2}$ & $\mathrm{H}_{2}$ & $\mathrm{CH}_{4}$ & $\mathrm{C}_{3} \mathrm{H}_{8}$ & $\mathrm{CH}_{2} \mathrm{Cl}_{2}$ & Toluene & $\alpha{ }^{* O 2}$ & $\alpha \underset{H 2}{* C 3 H 8}$ & $\alpha_{N 2}^{* C H 2 C l 2}$ & $\alpha{ }_{N 2}^{* \text { Tolune }}$ \\
\hline BPDMS & 300 & 650 & 600 & 850 & 7200 & 52000 & 220000 & 2.2 & 12 & 133 & 730 \\
\hline PTMSP & $\begin{array}{c}3 \\
500\end{array}$ & 6000 & 22700 & 6500 & $\begin{array}{c}33 \\
800\end{array}$ & $\begin{array}{l}200 \\
000\end{array}$ & 750000 & 1.7 & 1.5 & 52 & 214 \\
\hline PI [8] & $\begin{array}{c}5 \\
10^{-2}\end{array}$ & $3 \underset{1}{310^{-}}$ & 8 & $5 \underbrace{10^{-}}_{3}$ & $210^{-3}$ & - & - & 6 & $410^{-4}$ & - & - \\
\hline
\end{tabular}

Table 1: Permeability and ideal selectivity of block copolydimethylsiloxane-urea (BPDMS), polytrimethylsilyl propyne (PTMSP) and polyetherimide (PI) at $25^{\circ} \mathrm{C}$ 
They show clearly the extremely high permeability of PTMSP despite its glassy feature when compares to the rubbery siloxane membrane that is however one the most permeable membrane.

The data also demonstrates the established conflict variations of $\mathscr{P}$ and $\alpha^{*}$. The qualitative influence of diffusion and sorption phenomena can be appreciated quite well within this series of results. The trend is the same for BPDMS and PTMSP and demonstrates the dramatic effect of condensable molecules. It can be seen that size sieving selectivity occurred only with inert gas mixtures that means the smallest molecule is selectively transported through the membrane. Conversely for VOC-gas mixtures the membrane selectivity favoured the organic molecules that mean the bigger molecules are in fact the fastest ones; this type of selectivity is called inverse selectivity.

When hydrogen - gas mixtures need to be purified, it is thus important to understand that membrane processes can induce the purification of hydrogen either in the retentate (feed side) or in the permeate downstream side according to the nature of the mixed gas and to the membrane permeation characteristics. Hence with a "true" glassy membrane such as aromatic polyimides (PI), the hydrogen enrichment will be obtained in the permeate side either versus $\mathrm{N}_{2}$ or propane, whereas with BPDMS or PTMSP the reverse situation will occur versus propane due to inverse selectivity mechanism. Hence it is clear that according to the composition of the feed and the use wanted of the purified gas, it could be wised to choose carefully the separation process taking into account the membrane separation potential. With respect to already industrialized gas purification technologies, membrane processes can provide original as well as energy saving solutions not affordable by other processes as shown above by the distinct hydrogen purification opportunities.

Investigation of a lab scale module based on PTMSP disk membranes for VOC recovery

A lab scale membrane module was constructed and tested in a close loop with a stripper to purify water effluents contaminated by low amounts of VOC $(<1 \mathrm{wt} \%)$. This module was prepared from stainless-steel porous disks (3-5 microns pore size) physically coated on both sides with PTMSP dense films (thickness about 8 microns). These disks showed enough stability in permeation of air during at least three months, the measurements being started after one month of preparation of polymeric films and elements (Fig.4). The module provided a high permeate flux ( 27 disks, diameter: $160 \mathrm{~mm}$, surface area $\mathrm{S}=0.75 \mathrm{~m}^{2}$ ) with only small decrease with time $(20 \%)$.

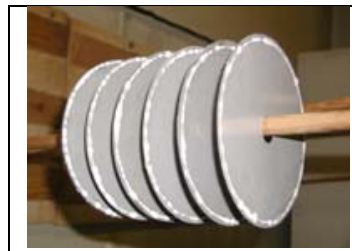

Figure 4: PTMSP disks: dense layer 8-9 microns

\begin{tabular}{cccc}
$\begin{array}{c}\text { Disk } \\
\text { number }\end{array}$ & $\begin{array}{c}\text { Permeate flux } \\
\mathrm{Nl} / \mathrm{m}^{2} \mathrm{~h}^{*} \text { bar }\end{array}$ & $\begin{array}{c}\text { Oxygen } \\
\text { Permeate } \%\end{array}$ & $\begin{array}{c}\text { Air separation: } \\
\mathrm{O}_{2} / \mathrm{N}_{2} \text { selectivity }\end{array}$ \\
\hline 1 & 190 & 32.3 & 1.9 \\
8 & 220 & 31.2 & 1.8 \\
29 & 190 & 31.5 & 1.9 \\
\hline \hline
\end{tabular}

Table 2: Primary characterization of disk element for air separation $\left(25^{\circ} \mathrm{C}\right)$

\begin{tabular}{|c|c|c|c|}
\cline { 2 - 4 } \multicolumn{1}{c|}{} & $\begin{array}{l}\text { Gas } \\
\text { Flux } \\
\text { L/h }\end{array}$ & $\begin{array}{l}\text { Liq } \\
\text { Flux } \\
\text { L/h }\end{array}$ & $\begin{array}{c}\text { Feed } \\
\text { purification } \\
\text { level }\end{array}$ \\
\hline$*$ Tol. & 600 & 40 & $88 \%$ \\
\hline$*$ DCl & 1150 & 33 & $83 \%$ \\
\hline
\end{tabular}

Table 3: Experimental hybrid system features for the recovery of VOC's

Based on these experimental data, the module performances were investigated in several engineering schemes for the VOCs recovery from gaseous or waste water streams by hybrid membrane system (Fig.5, Tab.2). One of the advantages of this hybrid membrane system with respect to more conventional adsorption gas treatment is the continuous aspect the overall process.

The main points studied were the characterization of the selected active polymer layer (i.e. PTMSP), the preparation of composite membrane disks necessary to achieve a module, the simulation of the stripping operation together with the membrane module separation and coupling, and the experimental tests at the bench scale. As typical case, the removal of toluene from water was considered under the following conditions: waste water flux of $\approx 1$ 
$\mathrm{m}^{3} / \mathrm{h}$ with a VOC concentration of $0.02-1 \mathrm{wt} \%$, stripping column of $2 \mathrm{~m}$ height, inert gas flux of $400-1000 \mathrm{NL} / \mathrm{h}$, module of $0.8 \mathrm{~m}^{2}$.

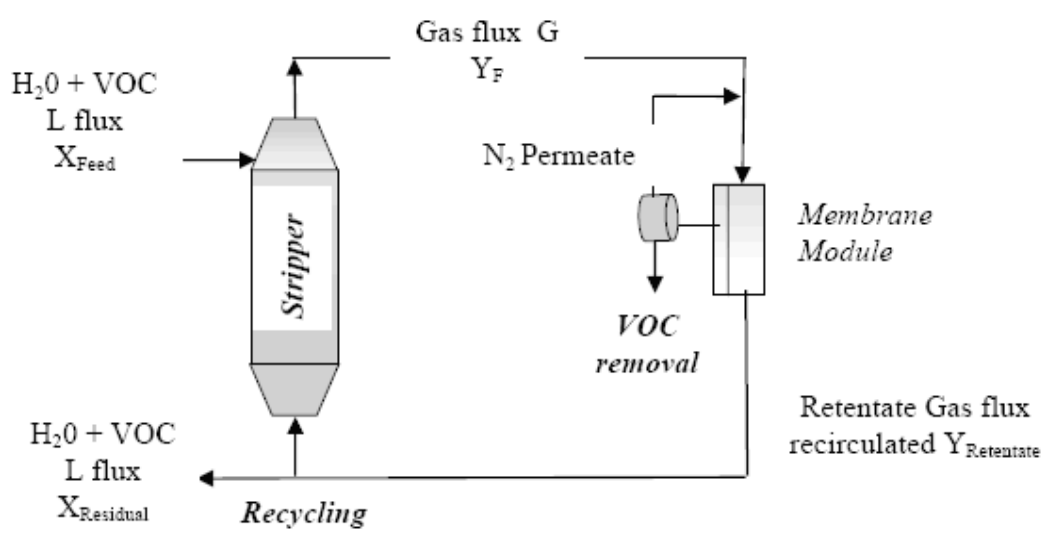

gas is re-circulated.
Figure 5:

Hybride membrane system scheme for the continuous removal of VOC from waste water streams.

The aqueous feed is stripped with the minimum of nitrogen to vaporized $90 \mathrm{wt} \%$ of VOC in the gas phase. This gas mixture is then purified by the membrane module quite easily thanks to the high membrane affinity for the VOC. The VOC is condensed and the stripping

The results given in the Tab.3 demonstrated the efficiency of the hybrid membrane system for the purification of aqueous feeds containing either Toluene $(0.017 \mathrm{wt} \%)$ or Dichloromethane $(0.015 \mathrm{wt} \%)$ as contaminant. More than $80 \%$ of the VOC could be stripped and condensed thanks to the membrane module under recirculation mode of the stripping gas.

\section{Conclusion}

The careful design and use of polymers and related membranes in separation processes can lead to innovative routes in energy and environment areas. Indeed dense membranes can provide new purification methods based on selective mass transfer due to molecular discrimination. The molecular parameters responsible of the selectivity are the size, the shape and the physico-chemical features of the molecules.

Acknowledgements. This work was supported by the $4^{\text {th }}$ European programme (IC15 CT 980140). L.Fefilatiev from CLIMBY Company, Moscow, and V.Lagunstsov from Moscow Engineering-Physical Institute Moscow are gratefully acknowledged from their help in the module achievement.

\section{Literature}

1. Barrer, R. M., Permeation, diffusion and solution of gases in organic polymers, Trans. Faraday Soc., v. 35, p. 628-643 (1939).

2. Loeb, S., Loeb-Sourirajan membrane: how it came about, ACS Symposium Series, p. 1-9 (1981).

3. Baker, R. W., Future directions of membrane gas separation technology, Industrial and Engineering Chemistry Research, v. 41, p. 1393-1411 (2002).

4. Mulder, M., Basic principles of membrane technology, $2^{\text {nd }}$ Ed.Kluwer Academic Press, London (1996).

5. Belet, F., Roizard, D., Lenda, H., Preparation and characterization of copolysiloxane-ureas highly permeable for VOC's, Entropie, n²35-236, 28-35 (2001).

6. Mercel, T.C., Bonda, V., Nagai, K., Freeman, B.D., J.Polym.Sci. Part B: Polym.Phys., V.38, 273-296, (2000).

7. Teplyakov, V., Roizard, D., Favre, E. and Khotimsky, V., Investigations on the peculiar permeation properties of volatile organic compounds and permanent gases through PTMSP, J. Membrane Science 220 (1-2): 165-175 (2003).

8. Syrtsova, D.A., Borisevich et col., The permeability of gases and light hydrocarbons through new polymeric composite membranes based onPTMSP, Separ. and Purific. Technol.57 (3), pp. 435-439 (2007)

9. Yampol'skii, Y., Polymer gas separation membranes, Chap.8, CRC Press, London (1994) 